\title{
Thermodynamic, chemical and electrochemical investigation of pandanus tectorius extract as corrosion inhibitor for steel in sulfuric acid solutions
}

\author{
Aisha Mahmood Al-Turkustani \\ Chemistry Department, Girls College, King Abdulaziz University, Jeddah, 21231, The Kingdom of Saudi Arabia \\ *Corresponding author at: Chemistry Department, Girls College, King Abdulaziz University, Jeddah, 21231, The Kingdom of Saudi Arabia. \\ Tel.: +966.504591895; fax: +966.26860854. E-mail address: a.m.turkustani@hotmail.com (A.M. Al-Turkustani).
}

\section{ARTICLE INFORMATION}

Received: 20 April 2013

Received in revised form: 06 June 2013

Accepted: 06 June 2013

Online: 31 December 2013

\section{KEYWORDS}

Steel

Sulfuric acid

Corrosion inhibition

Effect of temperature

Pandanus tectorius extract

Chemical and electrochemical measurements

\begin{abstract}
The corrosion inhibition characteristics of pandanus tectorius extract on corrosion of steel in 1 $\mathrm{M} \mathrm{H}_{2} \mathrm{SO}_{4}$ were investigated using chemical and electrochemical measurements at various temperatures $\left(30,40,50\right.$ and $\left.60^{\circ} \mathrm{C}\right)$. The effect of acid concentration on the corrosion rate of steel increases with acid concentration (0.25-2.00 M) showing first order corrosion reaction without changing the reaction mechanism. The results showed that when the concentration of pandanus tectorius extract increased from $5 \%$ to $15 \%(\mathrm{v}: \mathrm{v})$, the rate of steel corrosion is decreased, which indicated that pandanus tectorius extract are good inhibitor for steel corrosion in $1 \mathrm{M} \mathrm{H}_{2} \mathrm{SO}_{4}$ at $30{ }^{\circ} \mathrm{C}$ and attains $88.02 \%$ at $15 \%$ ( $v: v$ ) from weight loss method. Electrochemical results showed that the investigated extract was acted as mixed type inhibitor. The free energy of adsorption $\Delta G_{\text {ads }}$ for pandanus tectorius, indicates that the process was spontaneous and physically adsorbed (physisorption) onto the steel surface. Also, scanning electron microscopy (SEM) is used to support the obtained result. The trend of inhibition efficiency with temperature suggests physical adsorption of this extract on the corroding steel surface. Thermodynamic functions $\Delta E_{\text {app }}, \Delta H^{*}$ and $\Delta S^{*}$ has been calculated and are discussed.
\end{abstract}

\section{Introduction}

Corrosion is usually defined as the deterioration of a metal or its properties caused by a reaction with its environment [1]. In many industries, steel is the material of choice in the fabrication of reaction vessels, pipelines for petroleum industries, storage tanks and chemical batteries, etc., those all can be corroded easily in the presence of acids [2,3]. The industrial application of steel is attractive due to some unique properties it exhibits for most engineering requirements. Their applications have been driven by a number of issues, such as its low cost and availability for the manufacturing of reaction vessels; cooling tower reservoirs, pipelines [4]. Among the methods of corrosion control, use of inhibitors is very popular due to the ease of application.

Acids such as $\mathrm{HCl}$ and $\mathrm{H}_{2} \mathrm{SO}_{4}$ are widely used as pickling, descaling, oil well acidizing and cleaning agents in several industries for the removal of undesirable oxide films and corrosion products [5]. Due to their high corrosive nature, acids may cause damage to the system components. Various methods are used to decrease the corrosion rate of metals in acids, among the different methods use of inhibitors is most commonly used [5-8]. These are substances used to stop or slow-down the corrosion process.

Use of inhibitors is one of the most practical methods for protection against corrosion especially in acid solutions to prevent unexpected metal dissolution and acid consumption [9-11]. Different organic and inorganic compounds have been studied as inhibitors to protect metals from corrosion attack [12]. The ability of a compound to a serve as inhibitor is dependent on its ability to form a compact barrier film and/or nature of adsorption on metal surface [13-15]. Usually, organic compounds exert a significant influence on the extent of adsorption on the metal surface and therefore can be used as effective corrosion inhibitors. The efficiency of these organic corrosion inhibitors is related to the presence of polar functions with $\mathrm{S}, \mathrm{O}$ or $\mathrm{N}$ atoms in the molecule, heterocyclic compounds and $p$ electrons $[16,17]$. The polar function is usually regarded as the reaction center for the establishment of the adsorption process [18]. The known hazardous effects of most synthetic organic, inhibitors and restrictive environmental regulations have now made researchers to focus on the need to develop cheap and environmentally benign natural products as corrosion inhibitors. These natural organic compounds are either synthesized or extracted from aromatic herbs, spices and medicinal plants. Plant extracts are viewed as an incredibly rich source of naturally synthesized chemical compounds that can be extracted by simple procedures with low cost and are biodegradable in nature. This area of research is of much importance because in addition to being environmentally friendly and ecologically acceptable, plant products are inexpensive, readily available and renewable source of materials [19].

The aim of the present work is to find a naturally occurring, cheap and environmentally safe substance that could be used for inhibition of corrosion of steel in acidic medium. An attempt has been made to ascertain their corrosion inhibition properties. Therefore, in this present work, the aqueous extract of Pandanus tectorius in $1 \mathrm{M} \mathrm{H}_{2} \mathrm{SO}_{4}$ was tested by using chemical (weight loss $(W L$ ), hydrogen evolution $H E$ )) and electrochemical (Potentiodynamic polarization $(P)$, electrochemical impedance $(E I)$ ) techniques. SEM study was also used to study the surface morphologies.

Pandanus tectorius belongs to the family Pandanaceae, and

European Journal of Chemistry 
grows to a height of 5-8 meters (25 feet) with sharp to blunt spikes along the trunk [20] (Figure 1). According to Walter [21], P. tectorius is used as a food and medicine in the Marshalls, Yap, Hawaii, Tonga, and Tahiti. In these cultures, the aerial root is used to relieve several internal diseases including stomachache, food poisoning, and urinary tract problems $[22,23]$. Whistler [22], and Peungvicha et al. [24] reported that Pandanus tectorius leave was used for internal ailments, inflammation, sores, relieving stomachaches, and food poisoning.
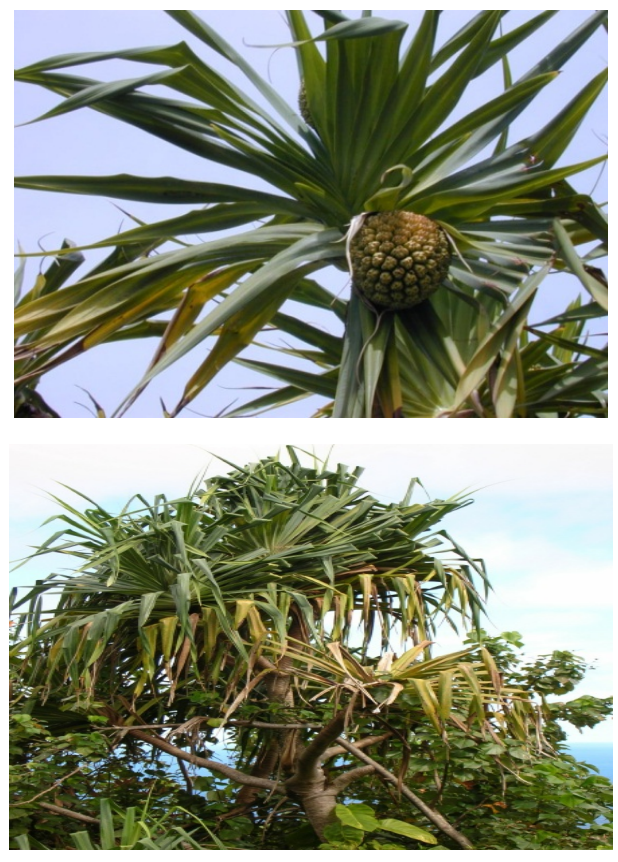

Figure 1. Pandanus tectorius tree.

\section{Experimental}

\subsection{Preparation of steel specimen}

Steel sample of size $5.0 \mathrm{~cm} \times 1.0 \mathrm{~cm}$ containing the composition of $0.14 \% \mathrm{C}, 0.35 \% \mathrm{Mn}, 0.17 \% \mathrm{Si}, 0.025 \% \mathrm{~S}, 0.03$ $\% \mathrm{P}$ and the remainder $\mathrm{Fe}$ was used for chemical methods (weight loss $(W L)$ and hydrogen evolution $(H E)$ ). For electrochemical studies, steel sample of the same composition but with an exposed area of $0.3316 \mathrm{~cm}^{2}$ were used. Steel samples were polished mechanically with emery papers from 60 to 1200 grades, subsequently degreased with bi-distilled water and finally with acetone. Accurate weight of the samples was taken using electronic balance.

\subsection{Preparation of the plant extract}

The leaves of the pandanus tectorius plant were taken and cut into small pieces, weighed and mixed with bi-distilled water in a bolinder (Electric mixer). The mixture was allowed to stand overnight in a refrigerator at low temperatures and then filtered through ordinary filter paper. From this stock solution, different concentrations of inhibitor solutions ranging from $1 \%$ to $15 \%$ were prepared.

\subsection{Weight loss method}

The pretreated specimen initial weight was noted and was immersed in the experimental solution. After one hour, the specimen was taken out, washed thoroughly with distilled water, and dried completely, and their final weight was noted.
The loss in weight was calculated and tabulated, then the corrosion rate $\left(\mathrm{g} / \mathrm{cm}^{2} \cdot \mathrm{min}\right)$, inhibition efficiency (IE\%), and surface coverage $(\theta)$ of plant extract was calculated using the formula [25],

Corrosion rate $\left(C R_{W L}\right)\left(\mathrm{g} / \mathrm{cm}^{2} \cdot \mathrm{min}\right)=\Delta W / A t$

where $W$ is weight loss in $g, A$ is area in $\mathrm{cm}^{2}, t$ is time in min.

Inhibition efficiency $\left(I E_{W L} \%\right)=C R_{B}-C R_{I} / C R_{B} \times 100$

Surface coverage $(\theta)=C R_{B}-C R_{I} / C R_{B}$

where $C R_{B}$ and $C R_{I}$ are corrosion rates in the absence (blank solution) and presence of the inhibitor.

\subsection{Hydrogen evolution method}

Hydrogen evolution method measures the volume of $\mathrm{H}_{2}$ gas evolution from the reaction system.

From the volume of hydrogen gas evolved per minute, corrosion rate $\left(\mathrm{mL} / \mathrm{cm}^{2} . \mathrm{min}\right)$, inhibition efficiency (IE\%) and degree of surface coverage $(\theta)$, were calculated using equations,

Corrosion rate $\left(C R_{H E}\right)\left(\mathrm{mL} / \mathrm{cm}^{2} \cdot \mathrm{min}\right)=\left(V_{H^{-}}-V_{I}\right) / t$

where $V_{\mathrm{I}}$ is the volume of hydrogen gas at time $t$ for inhibited solution and $V_{H}$ is the volume of hydrogen gas evolved at time $t$ for uninhibited solution.

Inhibition efficiency $\left(I E_{H E} \%\right)=C R_{B}-C R_{I} / C R_{B} \times 100$

Surface coverage $(\theta)=C R_{B}-C R_{I} / C R_{B}$

where $C R_{B}$ and $C R_{I}$ are corrosion rates in the absence (blank solution) and presence of the inhibitor.

\subsection{Potentiodynamic polarization method}

The polarization measurements were made to evaluate the corrosion potential $\left(E_{\text {corr. }}\right)$, corrosion current ( $\left.I_{\text {corr. }}\right)$, and Tafel slopes (anodic $\left(b_{a}\right)$ and cathodic $\left(b_{c}\right)$ ). Experiments were carried out in a conventional three-electrode cell assembly with working electrode as steel specimen of $0.3316 \mathrm{~cm}^{2}$ area, a rectangular Pt foil as the counter electrode, and the reference electrode as standard calomel electrode (SCE).

A time interval of 10-15 minutes was given for each experiment to attain the steady state open-circuit potential. The polarization was carried from a cathodic potential of -800 $\mathrm{mV}$ (versus SCE) to an anodic potential of $-200 \mathrm{mV}$ (versus SCE) at a sweep rate of $1 \mathrm{mV}$ per second. The inhibition efficiency was calculated using the formula,

Inhibition efficiency $\left(I E_{P} \%\right)=I_{\text {corr }}-I_{\text {corr }}^{\circ} / I_{\text {corr }} \times 100$

where $I_{\text {corr }}$ and $I^{\circ}$ corr are corrosion current in the absence and presence of inhibitor.

\subsection{Electrochemical impedance method}

The electrochemical AC-impedance measurements were also performed using electrode cell assembly as that used for potentiodynamic polarization studies.

A sine wave with amplitude of $10 \mathrm{mV}$ was superimposed on the steady open circuit potential. The real part $\left(Z^{\prime}\right)$ and the imaginary part $\left(Z^{\prime \prime}\right)$ were measured at various frequencies in the range of $100 \mathrm{KHz}$ to $10 \mathrm{MHz}$. A plot of $Z$ ' versus $Z$ " was made. From the plot, the charge transfer resistance $\left(R_{c t}\right)$ was calculated, and the double layer capacitance was then calculated using 
$C_{\mathrm{dl}}=1 / 2 \pi f \max R_{c t}$

where $R_{c t}$ is charge transfer resistance, and $C_{\mathrm{dl}}$ is double layer capacitance. The experiments were carried out in the absence and presence of different concentrations of inhibitors. The percentage of inhibition efficiency was calculated using

Inhibition efficiency $\left(I E_{R c t} \%\right)=R_{c t}^{*}-R_{c t} / R_{c t}^{*} \times 100$

where $R_{c t}^{*}$ and $R_{c t}$ are the charge transfer resistance in the presence and absence of inhibitor.

\subsection{Surface examination studies}

Surface examination of steel specimen in the absence and presence of the optimum concentration of the extract immersed for $1 \mathrm{~h}$ at $30{ }^{\circ} \mathrm{C}$ was studied using Digi scope II V2.

\section{Results and discussion}

\subsection{Effect of sulfuric acid concentration on steel corrosion at $30{ }^{\circ} \mathrm{C}$}

The influence of $\mathrm{H}_{2} \mathrm{SO}_{4}$ concentrations $(0.25,0.50,1.00,1.50$ and $2.00 \mathrm{M}$ ) on steel corrosion at $30^{\circ} \mathrm{C}$ is shown in Figure 2. It is clear that as the concentration of the $\mathrm{H}_{2} \mathrm{SO}_{4}$ solution increases, the slop of the straight lines also increases, indicating an increase in the dissolution of steel and increased of corrosion rate. The ideality of the straight lines in Figure 2 indicates the absence of any insoluble formed layer on the surface of the metal through the process of corrosion. The presence of induction period in the beginning of the interaction indicates the dissolution of the oxide layer formed on the surface of steel. The decrease of induction period in the beginning of the interaction with increasing acid concentration is detected. The rates of corrosion from ML and HE methods $\left(C R^{\wedge} \& C R\right)$ are recorded in Table 1, it is found that the rates of corrosion increases with increasing acid concentration, this indicates that steel corrosion in $\mathrm{H}_{2} \mathrm{SO}_{4}$ is concentration dependent.

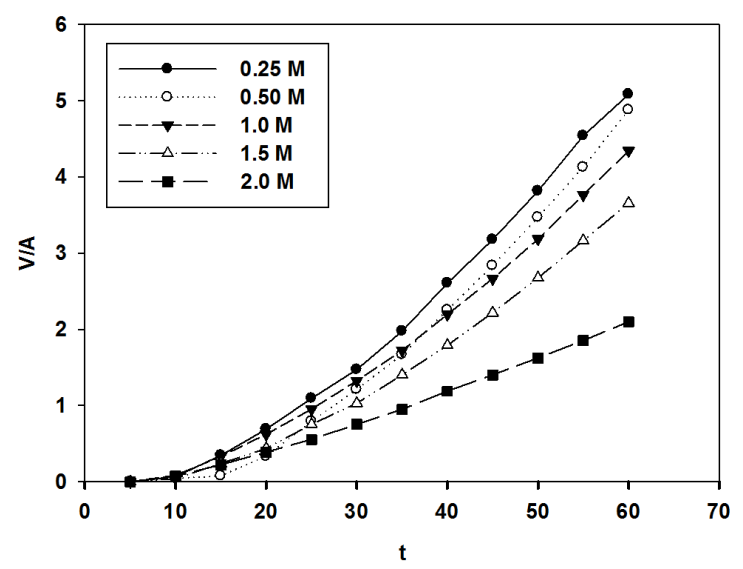

Figure 2. Volume of hydrogen evolution/time curves for the corrosion of steel in different concentrations of $\mathrm{H}_{2} \mathrm{SO}_{4}$ at $30{ }^{\circ} \mathrm{C}$. (As the concentration of the $\mathrm{H}_{2} \mathrm{SO}_{4}$ solution increases, the dissolution of steel and the corrosion rate are increased).

The relation between corrosion rate and acid concentration can be illustrated by the kinetic equation as:

$\log C R=\log A+n \log C$

where $A$ represents corrosion rate constant which represents the rate of metal dissolution (corrosion), $\mathrm{n}$ reaction order and $\mathrm{C}$ molar concentration of $\mathrm{H}_{2} \mathrm{SO}_{4}$ acid. The relationship log $\mathrm{CR}$ and /or $\log C R^{\prime}$ vs. $\log C$ gave a straight lines as in Figure 3.

The slopes of these lines represent the reaction order $(n)$ and the intercept is $\log \mathrm{A}$. It was found that the value of $\mathrm{n}$ is equal to unity indicating that corrosion of steel in $\mathrm{H}_{2} \mathrm{SO}_{4}$ solution is the first order reaction and depends on the concentration of $\mathrm{H}_{2} \mathrm{SO}_{4}$ acid.

Table 1. Corrosion rates for steel in different concentrations of $\mathrm{H}_{2} \mathrm{SO}_{4}$ at $30^{\circ} \mathrm{C}$.

\begin{tabular}{|c|c|c|}
\hline \multirow{2}{*}{$\begin{array}{l}\text { Concentration of } \mathrm{H}_{2} \mathrm{SO}_{4} \\
\text { (M) }\end{array}$} & \multicolumn{2}{|c|}{ Corrosion rate } \\
\hline & $\begin{array}{l}C R_{W L}^{\prime} \times 10^{4} \\
\left(\mathrm{~g} / \mathrm{cm}^{2} \cdot \mathrm{min}\right)\end{array}$ & $\begin{array}{l}C R_{H E} \\
\left(\mathrm{~mL} / \mathrm{cm}^{2} . \mathrm{min}\right)\end{array}$ \\
\hline 0.25 & 1.0236 & 0.0665 \\
\hline 0.50 & 1.9314 & 0.0920 \\
\hline 1.00 & 2.5123 & 0.1108 \\
\hline 1.50 & 3.3064 & 0.1684 \\
\hline 2.00 & 6.3931 & 0.2392 \\
\hline
\end{tabular}

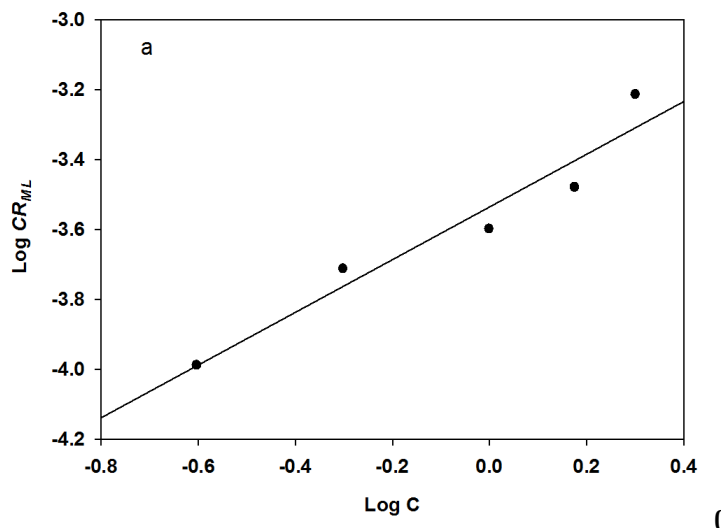

(a)

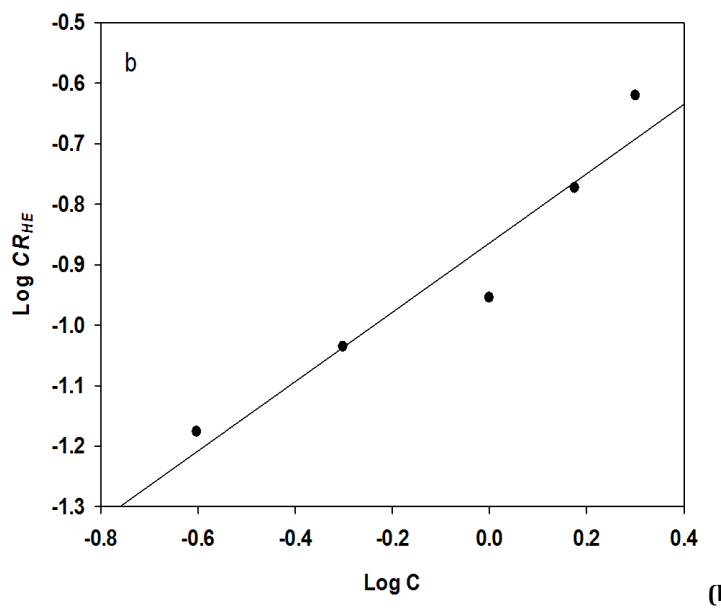

(b)

Figure 3. The relation between (a) $\log C R_{M L}$ and/or (b) $\log C R_{H E}$ for steel and $\log \mathrm{C}$ of $\mathrm{H}_{2} \mathrm{SO}_{4}$. (The corrosion of steel in $\mathrm{H}_{2} \mathrm{SO}_{4}$ solution is the first order reaction and depends on the concentration of $\mathrm{H}_{2} \mathrm{SO}_{4}$ acid)

\subsection{Effect of extract concentration on steel corrosion in $1 \mathrm{M}$ $\mathrm{H}_{2} \mathrm{SO}_{4}$ at $30{ }^{\circ} \mathrm{C}$}

\subsubsection{Weight loss studies}

The various corrosion parameters such as corrosion rate $(C R)$, inhibition efficiency $(I E)$, and surface coverage $(\theta)$ were obtained from weight loss method in $1 \mathrm{M}$ sulphuric acid in the absence and presence of different concentrations of the pandanus tectorius leaves extract ranging from $1 \%$ to $15 \%$ (v:v) and listed in Table 2. It was found that the maximum inhibition efficiency is $88.02 \%$ at $15 \%(v: v)$ and 1 hour of immersion. This 
result indicates that the pandanus tectorius extract could acts as corrosion inhibitor.

Table 2. Corrosion rates and inhibition efficiencies for steel in $1 \mathrm{M} \mathrm{H}_{2} \mathrm{SO}_{4}$ in the presence of different concentrations of pandanus tectorius leaves extract at $30^{\circ} \mathrm{C}$.

\begin{tabular}{|c|c|c|c|c|}
\hline \multirow[t]{2}{*}{$C_{\text {inh }}(\% v: v)$} & \multicolumn{2}{|c|}{ Corrosion rate } & \multicolumn{2}{|c|}{ Inhibition efficiency } \\
\hline & $\begin{array}{l}C R_{W L}^{\prime} \times 10^{4} \\
\left(\mathrm{~g} / \mathrm{cm}^{2} . \mathrm{min}\right)\end{array}$ & $\begin{array}{l}C R_{H E} \\
\left(\mathrm{~mL} / \mathrm{cm}^{2} \cdot \mathrm{min}\right)\end{array}$ & $I E_{W L} \%$ & $I E_{H E} \%$ \\
\hline 0.0 & 2.5123 & 0.1108 & - & - \\
\hline 1.0 & 1.6180 & 0.0713 & 35.59 & 35.64 \\
\hline 5.0 & 1.0473 & 0.0470 & 58.31 & 57.58 \\
\hline 10.0 & 0.3529 & 0.0189 & 85.95 & 82.94 \\
\hline 15.0 & 0.3010 & 0.0139 & 88.02 & 87.46 \\
\hline
\end{tabular}

\subsubsection{Hydrogen evolution studies}

The corrosion rates of steel in the absence and presence of different concentrations of pandanus tectorius leaves extract was monitored from the volume of hydrogen gas evolved at fixed time intervals. Figure 4 shows representative plots of the volume of hydrogen gas evolved as a function of reaction time at $30{ }^{\circ} \mathrm{C}$ for steel in $1 \mathrm{M} \mathrm{H}_{2} \mathrm{SO}_{4}$ without and with different concentrations of pandanus tectorius extract. It is observed from the figure that the volume of hydrogen gas evolved varies linearly with time and it is was less in the presence of plant extract compared to the blank solution.

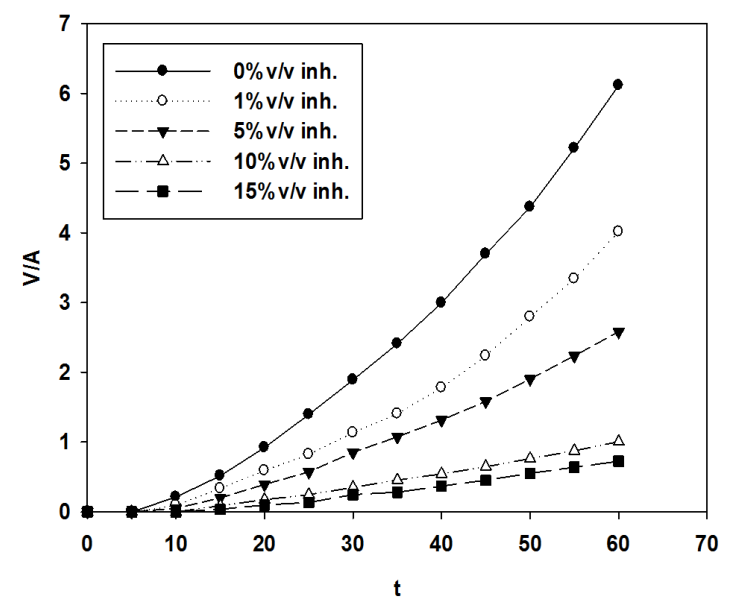

Figure 4. Volume of hydrogen evolution/time curves for the corrosion of steel in $1 \mathrm{M} \mathrm{H}_{2} \mathrm{SO}_{4}$ in the presence of different concentrations of aqueous extract of pandanas tictorius leaves at $30{ }^{\circ} \mathrm{C}$. (The corrosion rate of steel is less in the presence of plant extract compared to the blank solution).

Table 2 presents the computed values of the hydrogen evolution rates and the inhibition efficiency of the various concentrations of pandanus tectorius leaves extract. Results in the table reveal that the rates of hydrogen evolution were reduced on the introduction of the pandanus tectorius leaves extract to the uninhibited solution. The increase of the rate of hydrogen evolution in the uninhibited solution can be rationalized on the basis that sulphuric acid reacts with iron and forms metal sulphates that are soluble in aqueous media [26]. There are two reactions occurring, namely the anodic reaction and cathodic reaction. The equations 11 and 12 represent iron reaction in acidic solutions $[26,27]$.

Anodic reaction (oxidation reaction):

$\mathrm{Fe} \rightarrow \mathrm{Fe}^{+2}+2 \mathrm{e}^{-}$

Cathodic (reduction reaction or hydrogen evolution reaction):

$2 \mathrm{H}^{+}+2 \mathrm{e}^{-} \rightarrow \mathrm{H}_{2}$
This suggests that the components of the pandanus tectorius leaves extract are adsorbed onto the metal surface and block the electrochemical reaction efficiently by decreasing the available surface area. The values of inhibition efficiency are also listed in Table 2 can be seen to follow the trend reported for weight loss measurements.

\subsubsection{Potentiodynamic polarization studies}

Electrochemical corrosion kinetic parameters such as $E_{\text {corr, }}$ $I_{\text {corr, }} b_{a}, b_{c}$, and $I E_{p}$ for the corrosion of steel in $1 \mathrm{M} \mathrm{H}_{2} \mathrm{SO}_{4}$ at $30{ }^{\circ} \mathrm{C}$ in the absence and presence of different concentrations (5\% and $15 \%(v: v)$ ) of the pandanus tectorius extract are given in Table 3, and its corresponding polarization curves are shown in Figure 5. Potentiodynamic polarization studies revealed that the corrosion current density ( $\left.I_{c o r r}\right)$ markedly decreased with the addition of the inhibitor and the corrosion potential $\left(E_{\text {corr. }}\right)$ shifts to more negative values upon addition of the plant extract. Moreover, the values of anodic and cathodic Tafel slopes $\left(b_{a}\right.$ and $b_{c}$ ) are slightly changed indicating that this behavior reflects the plant extracts ability to inhibit the corrosion of steel in $1 \mathrm{M} \mathrm{H}_{2} \mathrm{SO}_{4}$ solution via the adsorption of its molecules on both anodic and cathodic sites, and, consequently, the extract acts through mixed mode of inhibition [28,29]. It was observed that with increase in concentration of the pandanus tectorius extract from $5 \%$ to $15 \%$, the maximum inhibition efficiency varied from $59.44 \%$ to $87.01 \%$.

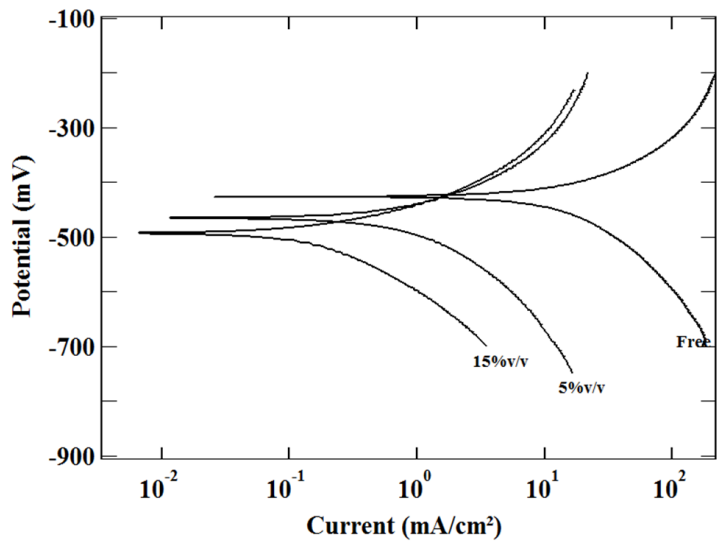

Figure 5. Potentiodynamic polarization curves for steel in $1 \mathrm{M} \mathrm{H}_{2} \mathrm{SO}_{4}$ solution in the absence and presence of $5 \%(v: v)$ and $15 \%(v: v)$ of the pandanus tectorius extract at $30{ }^{\circ} \mathrm{C}$. (The extract acts as mixed type of inhibitor, with increase in concentration of the pandanus tectorius extract from $5 \%$ to $15 \%$, the maximum inhibition efficiency varied from $59.44 \%$ to $87.01 \%$ ).

\subsubsection{Electrochemical impedance studies}

Impedance measurements were studied to evaluate the charge-transfer resistance $\left(R_{c t}\right)$ and double-layer capacitance $\left(C_{d l}\right)$, and through these parameters the inhibition efficiency was calculated. Figure 6 shows the impedance diagrams for steel in $1 \mathrm{M} \mathrm{H}_{2} \mathrm{SO}_{4}$ with $5 \%$ and/or $15 \%$ ( $\left.v: v\right)$ of the pandanus tectorius leaves extract, and the impedance parameters derived from these investigations are given in Table 3. From Figure 6, the obtained impedance diagrams are almost in a semicircular appearance, indicating that the charge-transfer process mainly controls the corrosion of steel. Deviations of perfect circular shape are often referred to the frequency dispersion of interfacial impedance. This anomalous phenomenon may be attributed to the inhomogeneity of the electrode surface arising from surface roughness or interfacial phenomena. In fact, in the presence of the plant extract, the values of $R_{c t}$ have enhanced and the values of $C_{d l}$ are also brought down to the maximum extent. 
Table 3. Potentiodynamic polarization and impedance parameters for the corrosion of steel in $1 \mathrm{M} \mathrm{H}_{2} \mathrm{SO}_{4}$ in the absence and presence of $5 \%$ ( $v: v$ ) and $15 \%$ ( $v: v$ ) of the pandanus tectorius extract at $30^{\circ} \mathrm{C}$

\begin{tabular}{|c|c|c|c|c|c|c|c|c|}
\hline \multirow[t]{2}{*}{ Concentration of extract $(\% v: v)$} & \multicolumn{5}{|c|}{ Polarization } & \multicolumn{3}{|l|}{ Impedance } \\
\hline & $-E_{\text {corr. }}(\mathrm{mV})$ & $I_{\text {corr. }}\left(\mathrm{mA} / \mathrm{cm}^{2}\right)$ & $b_{a}$ & $\boldsymbol{b}_{c}$ & $I E_{p} \%$ & $\left.R_{c t}(\mathbf{\Omega . c m})^{2}\right)$ & $C_{d l}\left(\mathrm{~F} / \mathrm{cm}^{2}\right)$ & $I E_{R c t} \%$ \\
\hline Blank & 426.98 & 3.859 & 141.14 & 214.84 & 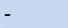 & 43.53 & $2.15 \times 10^{-4}$ & - \\
\hline 5 & 462.44 & 1.565 & 107.55 & 164.94 & 59.44 & 105.30 & $5.52 \times 10^{-5}$ & 58.66 \\
\hline 15 & 488.23 & 0.5011 & 59.026 & 131.46 & 87.01 & 282.53 & $1.99 \times 10^{-5}$ & 84.60 \\
\hline
\end{tabular}

The decrease in $C_{d l}$ shows that the adsorption of the inhibitor takes place on the metal surface in acidic solution. The inhibition efficiency obtained as $58.66 \%$ at $5 \%(v: v)$ and $84.60 \%$ at $15 \%(v: v)$.

A good agreement is observed between the results of chemical methods (weight loss and hydrogen evolution) and electrochemical methods (potentiodynamic polarization and impedance).

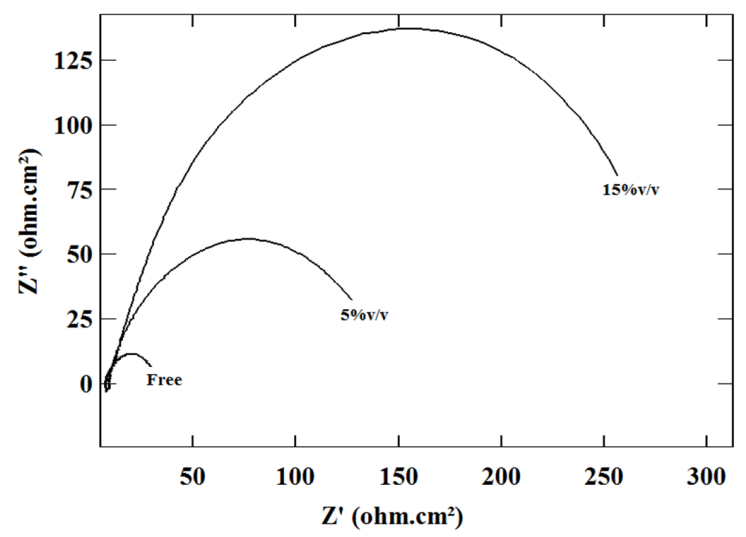

Figure 6. Impedance diagrams for steel in $1 \mathrm{M} \mathrm{H}_{2} \mathrm{SO}_{4}$ solution in the absence and presence of $5 \%(v: v)$ and $15 \%(v: v)$ of the pandanus tectorius extract at $30{ }^{\circ} \mathrm{C}$. (The inhibition efficiency obtained as $58.66 \%$ at $5 \%(v: v)$ and $84.60 \%$ at $15 \%(v: v))$.

\subsection{Kinetics and mechanism of corrosion inhibition}

Figure 7 shows the relation between $I E \%$ and inhibitor concentration $C_{\text {inh }}$ for the investigated extract from Hydrogen evolution (Gasometric) and weight loss (Gravimetric) methods. As can be readily seen, the plots have the form of $S$-shaped adsorption. This indicates that the aqueous extract of pandanus tectorius plant inhibit the acid dissolution for steel by adsorption of the molecules of the pandanus tectorius plant at metal acid solution interface, also the obtained figure indicated one step of adsorption.

Inspection of the chemical structures of the phytochemical constituents reveals that the compounds in this plant are isopentenyl and dimethylallyl acetates and cinnamates in large amounts in an essential oil obtained from the leaves of Pandanus tectorius [30] and they are oxygen compounds with $\mathrm{OH}$ group which easily hydrolysable and can adsorb on the metal surface via the lone pair of electrons present on their oxygen atoms and make a barrier for charge and mass transfer leading to decreasing the interaction of the metal with the corrosive environment. As a result, the corrosion rate of the metal was decreased. The formation of film layer essentially blocks discharge of $\mathrm{H}^{+}$and dissolution of metal ions. Due to electrostatic interaction, the protonated constituent's molecules are adsorbed (physisorption) and high inhibition is expected. Acid pickling inhibitors containing organic N, S, and $\mathrm{OH}$ groups behave similarly to inhibit corrosion [31].

The inhibition of the corrosion of steel in $1 \mathrm{M} \mathrm{H}_{2} \mathrm{SO}_{4}$ medium with addition of different concentrations of the extract can be explained by the adsorption of the components of the plant extract on the metal surface. Inhibition efficiency $(I E)$ is directly proportional to the fraction of the surface covered $(\theta)$ by the adsorbed molecules. Therefore, $(\theta)$ with the extract concentration specifies the adsorption isotherm that describes the system and gives the relationship between the coverage of an interface with the adsorbed species and the concentration of species in solution. The values of the degree of surface coverage $(\theta)$ were evaluated at different concentrations of the inhibitors in $1 \mathrm{M} \mathrm{H}_{2} \mathrm{SO}_{4}$ solution from WL and $\mathrm{HE}$ methods. Attempts were made to fit $\theta$ values to various adsorption isotherms.

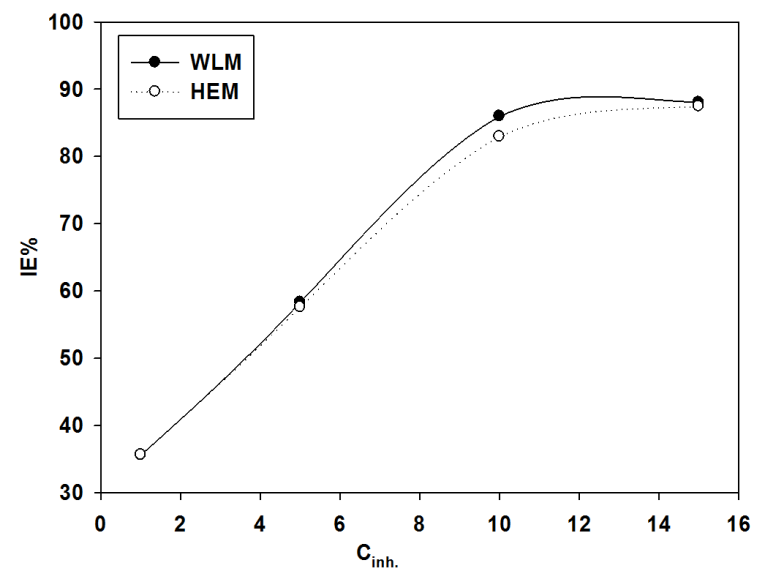

Figure 7. The variation of inhibition efficiency (IE\%) against $\log \mathrm{C}_{\text {inh. }}$ for steel in $1 \mathrm{M} \mathrm{H}_{2} \mathrm{SO}_{4}$ in the absence and presence of pandanas tictorius leaves extract at $30^{\circ} \mathrm{C}$. (The aqueous extract of pandanus tectorius plant inhibit the acid dissolution for steel by adsorption of the molecules of the pandanus tectorius plant at metal acid solution interface and the adsorption was done in one step).

On examining, the adsorption of different concentrations of pandanus tectorius extract on the surface of steel in $1 \mathrm{M}$ sulphuric acid was found to obey Langmuir adsorption isotherm.

Langmuir adsorption isotherm equation [31].

$\theta / \mathrm{C}=1 / K+\mathrm{C}$

where $\mathrm{C}$ is the concentration of aqueous extract of pandanus tectorius plant, $K$ is adsorption constant and $\theta$ is degree of coverage.

The Langmuir adsorption isotherm plot for the adsorption of various concentrations of the plant extract is shown in Figure 8.

The standard free energy of adsorption $\Delta G^{\circ}$ ads which can characterize the interaction of adsorption molecules and metal surface was calculated

$\operatorname{Ln} K=\ln 1 / 55.5-\Delta G_{\text {ads }}^{\circ} / R T$

where one molecule of water is replaced by one molecule of inhibitor and the numerical value $(1 / 55.5)$ in the equation stands for the molarity of water. The value of $K$ can be calculated using

$K=\theta /(1-\theta) C$ 
Table 4. Corrosion rates for steel in $1 \mathrm{M} \mathrm{H}_{2} \mathrm{SO}_{4}$ with different concentration of aqueous extract of pandanus tectorius at different temperature.

\begin{tabular}{|c|c|c|c|c|c|c|}
\hline \multirow[t]{3}{*}{ Temperature (t) } & \multicolumn{4}{|c|}{ Corrosion rate } & \multicolumn{2}{|c|}{ Inhibition efficiency } \\
\hline & \multicolumn{2}{|c|}{$C R_{\mathrm{WL}} \times 10^{4}\left(\mathrm{~g} / \mathrm{cm}^{2} \cdot \mathrm{min}\right)$} & \multicolumn{2}{|c|}{$C R_{\mathrm{HEn}}\left(\mathrm{mL} / \mathrm{cm}^{2} \cdot \mathrm{min}\right)$} & \multirow{2}{*}{$I E_{\mathrm{WL}} \%$} & \multirow[t]{2}{*}{$I E_{\mathrm{HE}} \%$} \\
\hline & $0 \%(v: v)$ & $5 \%(v: v)$ & $0 \%(v: v)$ & $5 \%(v: v)$ & & \\
\hline$\overline{30}$ & 2.5123 & 1.0473 & 0.1108 & 0.0470 & 58.31 & 57.09 \\
\hline 40 & 6.2469 & 2.7995 & 0.2582 & 0.1196 & 55.18 & 53.68 \\
\hline 50 & 12.7250 & 9.3975 & 0.5202 & 0.3997 & 26.15 & 23.16 \\
\hline 60 & 22.615 & 19.606 & 0.9305 & 0.8361 & 13.31 & 10.15 \\
\hline
\end{tabular}

The values of $\Delta G_{\text {ads }}^{\circ}$ around $-20 \mathrm{~kJ} / \mathrm{mol}$ or lower are consistent with the electrostatic interaction between organic charged molecules and the charged metal (physisorption) and those around $-40 \mathrm{~kJ} / \mathrm{mol}$ or higher involved charge sharing or transfer from the organic molecules to the metal surface to format coordinate type of bond (chemisorption) as discussed by Moretti et al. [32]. In this case, the negative sign of free energy of adsorption for the plant extract indicates that the adsorption of the plant extract on steel surface was a spontaneous process and the adsorption could be physisorption, where $\Delta G_{\text {ads }}^{\circ}$ is equal $-10.60 \mathrm{~kJ} / \mathrm{mol}$. Studies of El-Etre [33] and Li et al. [34] reported similar kind of results. .

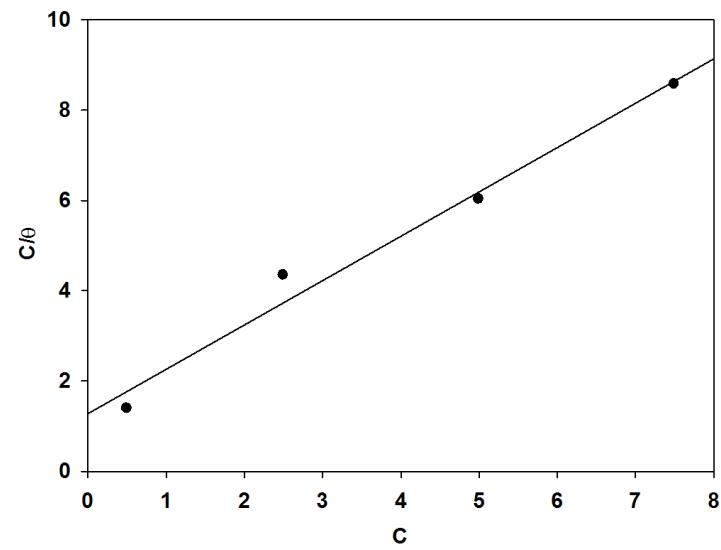

Figure 8. The relation between $\mathrm{C} / \theta$ against $\mathrm{C}_{\text {inh. }}$ of aqueous extract of pandanus tectorius for steel corrosion in $1 \mathrm{M} \mathrm{H}_{2} \mathrm{SO}_{4}$ at $30{ }^{\circ} \mathrm{C}$ (Langmiur isotherm).

\subsection{Surface examination studies}

Surface examination of the steel specimen was made using Digi scope II V2. The steel specimen after immersion in $1 \mathrm{M}$ $\mathrm{H}_{2} \mathrm{SO}_{4}$ solution for one hour at $30{ }^{\circ} \mathrm{C}$ in the absence and presence of $15 \%(v: v)$ of the plant extract were taken out, dried, and kept in a dessicator. The protective film formed on the surface of the steel was confirmed by SEM studies (Figure 9a and b). It was found that more grains were found in SEM image of steel immersed in $1 \mathrm{M} \mathrm{H}_{2} \mathrm{SO}_{4}$ solution in the absence of the inhibitor (Figure 9a), whereas no grains were found in the SEM image of steel immersed in $1 \mathrm{M} \mathrm{H}_{2} \mathrm{SO}_{4}$ solution in the presence of $15 \%(v: v)$ of the extract (Figure 9b), which shows the presence of a protective film over the surface of the steel in the presence of the inhibitor.

The SEM morphology of the adsorbed protective film on the steel surface has confirmed the high performance of inhibitive effect of the plant extract.

\subsection{Effect of temperature}

Temperature can modify the interaction between the steel electrode and the acidic medium in the absence and the presence 5\% (v:v) (which give an average value of inhibition efficiency) of inhibitor (pandanus tectorius) extract. To assess the influence of temperature on corrosion and corrosion inhibition processes, the weight loss and hydrogen evolution measurements were carried out at $30-60{ }^{\circ} \mathrm{C}$ temperature range and given in Figures 10 and 11 and Table 4.
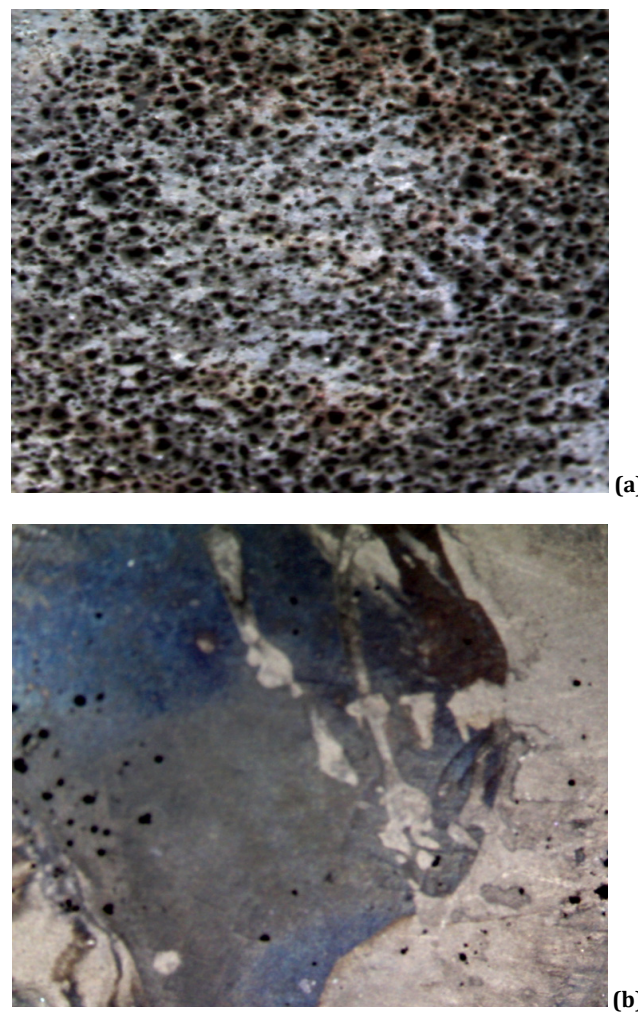

Figure 9. SEM of the steel surface in (a) $1 \mathrm{M} \mathrm{H}_{2} \mathrm{SO}_{4}$ and (b) $1 \mathrm{M} \mathrm{H}_{2} \mathrm{SO}_{4}+15 \%$ $(v: v)$ of plant extract at $30{ }^{\circ} \mathrm{C}$. (Grains were found in the absence of the inhibitor and the presence of a protective film over the surface of the steel in the presence of the inhibitor)

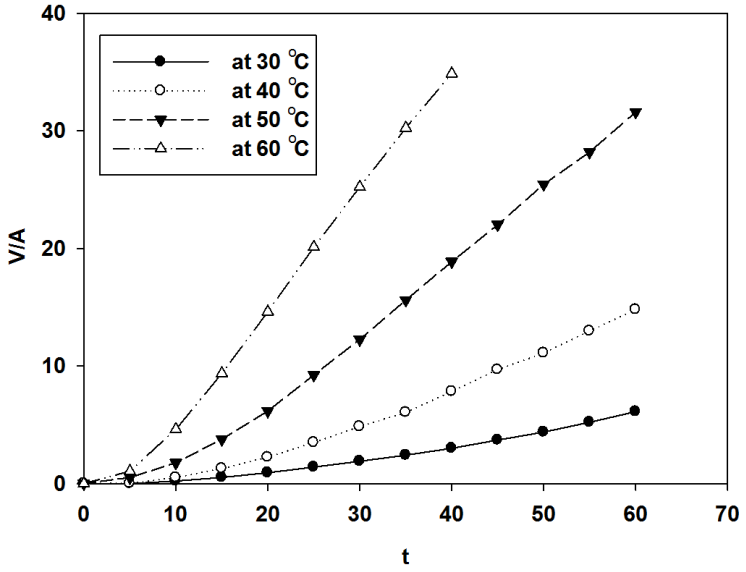

Figure 10. Volume of hydrogen evolution/time curves for steel corrosion in $1 \mathrm{M} \mathrm{H}_{2} \mathrm{SO}_{4}$ at different temperatures. 


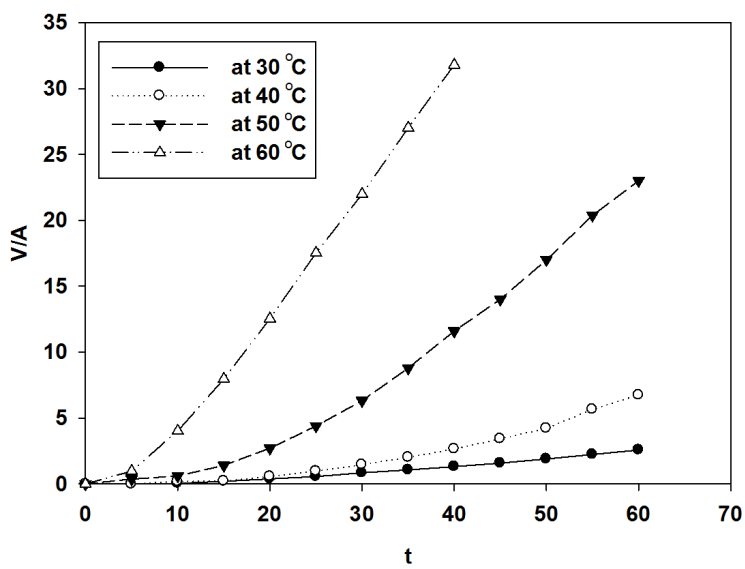

Figure 11. Volume of hydrogen evolution/time curves for steel corrosion in $1 \mathrm{M} \mathrm{H}_{2} \mathrm{SO}_{4}$ in the presence of $5 \%(\mathrm{v}: \mathrm{v})$ of aqueous extract of pandanas tictorius leaves at different temperatures. (Corrosion rates increase with rise of temperature both in uninhibited and inhibited solutions).

The results obtained indicated that corrosion rates increase with rise of temperature both in uninhibited and inhibited solutions. Figure 12 shows the relation between IE\% against temperature $(\mathrm{t})$ from both WL and HE methods. The decrease in inhibition efficiency with increasing temperature may be attributed to a possible shift of the adsorption-desorption equilibrium towards desorption of some adsorbed inhibitor molecules from the steel surface due to increased solution agitation resulting from higher rates of $\mathrm{H}_{2}$ gas evolution at higher temperatures. This shows a weak adsorption interaction between steel surface and the inhibitor $[35,36]$.

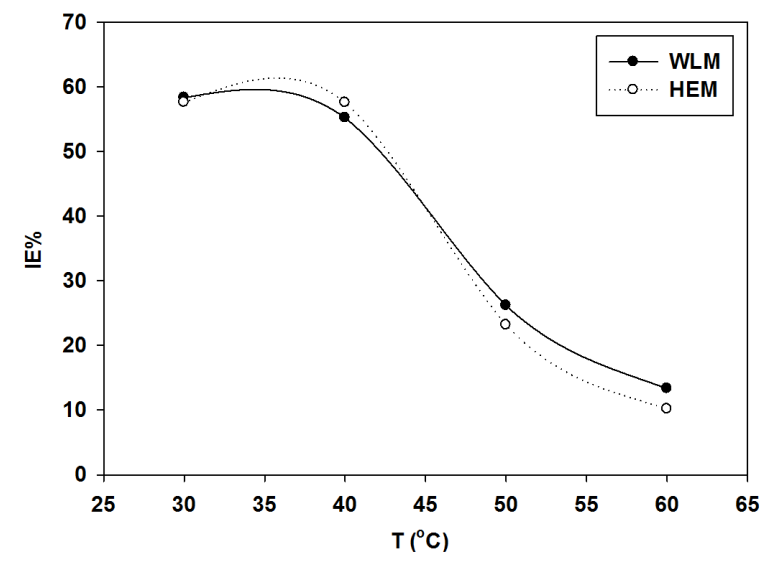

Figure 12. Plots of $I E \%$ vs. temperature (t) for steel in $1 \mathrm{M} \mathrm{H}_{2} \mathrm{SO}_{4}$ in the presence of $5 \%(v: v)$ pandanus tectorius extract. (The inhibition efficiency decrease with increasing temperature).

The dependence of corrosion rate on the temperature can be regarded as an Arrhenius-type process, the rate of which is given by [37]:

$\log C R=\log \mathrm{A}-E_{\mathrm{a}} / 2.303 \mathrm{R} T$

where $C R$ is the corrosion rate, $E_{\mathrm{a}}$ is the apparent activation energy, $\mathrm{R}$ is the molar gas constant, $T$ is the absolute temperature and $\mathrm{A}$ is the frequency factor.

The Arrhenius plot is shown in Figure 13 for steel in free acid solution and inhibited solution containing $5 \%(v: v)$ aqueous extract of pandanas tectorius plant from weight loss method. Linear plots were obtained from the slope
$\left(E_{\mathrm{a}} / 2.303 . \mathrm{R}\right)$, activation energy $\left(E_{\mathrm{a}}\right)$ values are deduced and listed in Table 5.

Table 5. Activation parameters for steel corrosion in $1 \mathrm{M} \mathrm{H}_{2} \mathrm{SO}_{4}$ in the absence and presence of $5 \%$ (v:v) Pandanus tectorius extract from weight loss method.

\begin{tabular}{llll}
\hline Concentration & $\boldsymbol{E}_{\mathrm{a}}(\mathrm{kJ} / \mathrm{mol})$ & $\boldsymbol{\Delta} \boldsymbol{H}^{*}(\mathrm{~kJ} / \mathbf{m o l})$ & $\boldsymbol{\Delta} \boldsymbol{S}^{*}(\mathbf{J} / \mathbf{m o l} . \mathbf{K})$ \\
\hline Blank & 19.54 & 18.71 & -76.38 \\
5\% $(v: v)$ & 25.04 & 27.94 & -8.95
\end{tabular}

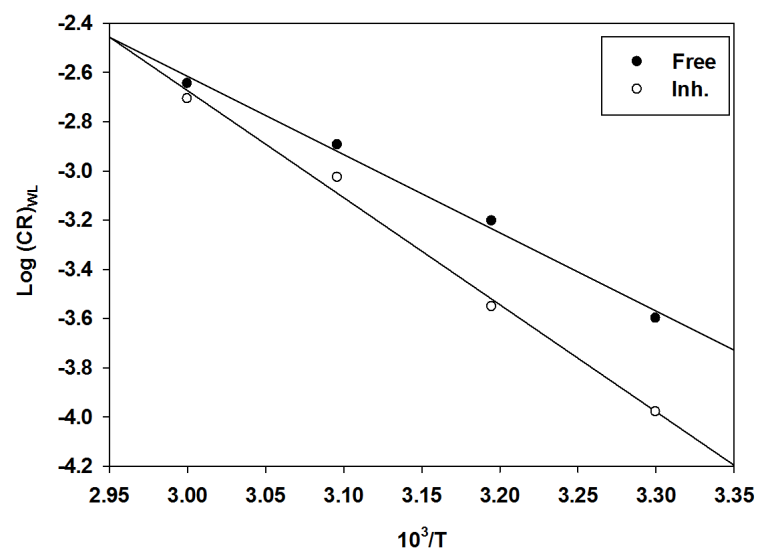

Figure 13. Arrhenius plot for steel in $1 \mathrm{M} \mathrm{H}_{2} \mathrm{SO}_{4}$ without and with $5 \%$ (v:v) pandanus tectorius extract.

The temperature dependence of the inhibiting effect and the comparison of the values of the apparent activation energy of the corrosion process in the absence and presence of inhibitor can provide further evidence [38] concerning the mechanism of the inhibiting action. The decrease of the inhibitor efficiency with temperature rise, which refers to a higher value of $E_{\mathrm{a}}$, when compared to that in an acid with no inhibitor, is interpreted as an indication for an electrostatic character of the inhibitor adsorption. The lower value of $E_{\mathrm{a}}$ in an inhibited solution when compared to that of an uninhibited one shows that strong chemisorption bond between the inhibitor and the metal is highly probable [39]. Activation energy, Ea values in the table are higher for inhibited solution (for the studied extract) than the uninhibited one, indicating a strong inhibitive action of the additive by increasing energy barrier for the corrosion process, emphasizing the electrostatic character of the inhibitor adsorption on the steel surface (physisorption). Experimental corrosion rate values obtained from weight loss measurement for steel in $1 \mathrm{M} \mathrm{H}_{2} \mathrm{SO}_{4}$ in the absence and presence of extract was used to further gain insight on the change of enthalpy $\left(\Delta H^{*}\right)$ and the entropy $\left(\Delta S^{*}\right)$ of activation complex in the transition state using transition state equation [40].

$\log C R / \mathrm{T}=\left[(\log (\mathrm{R} / \mathrm{N} . \mathrm{h}))+\Delta \mathrm{S}^{*} / 2.303 . \mathrm{R}\right)-\Delta H^{*} / 2.303 . \mathrm{R} . \mathrm{T}$

where $C R$ is the corrosion rate, $\mathrm{h}$ is the plank's constant, $\mathrm{N}$ is the Avogadro's number, $\mathrm{R}$ is the universal gas constant and $\mathrm{T}$ is the absolute temperature. Figure 14 shows the plot of log $(C R / \mathrm{T})$ vs. $1 / \mathrm{T}$ for steel corrosion in $1 \mathrm{M} \mathrm{H}_{2} \mathrm{SO}_{4}$ for the extract studied. Straight lines were obtained with slope of ($\left.\Delta H^{*} / 2.303 . \mathrm{R}\right)$ and intercept of $[\log (\mathrm{R} / \mathrm{N} . \mathrm{h})+(\Delta S / 2.303 . \mathrm{R})]$ from which the values of $\Delta H^{*}$ and $\Delta S^{*}$, respectively, were calculated and listed in Table 5 . The positive values of $\Delta H$ both in the absence and presence additive reflect the endothermic nature of the steel dissolution process and it indicates that the dissolution of steel is difficult [41]. Large and negative values of $\Delta S^{*}$ in the uninhibited and inhibited systems imply that the activation complex in the rate determining steps represents association rather than dissociation step, meaning that a 
decrease in disordering takes place on going from reactants to the activated complex. Similar observations have been reported in the literature for steel dissolution in the absence and presence of inhibitors in $\mathrm{H}_{2} \mathrm{SO}_{4}$ solution [42].

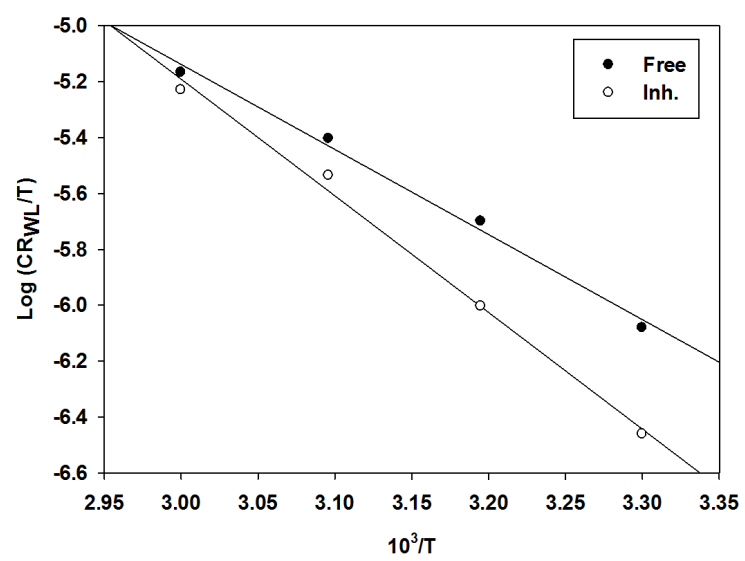

Figure 14. Transition state plot for steel in $1 \mathrm{M} \mathrm{H}_{2} \mathrm{SO}_{4}$ without and with $5 \%$ $(v: v)$ pandanus tectorius extract.

\section{Conclusion}

The corrosion rate of steel increases with increasing $\mathrm{H}_{2} \mathrm{SO}_{4}$ acid concentration 0.25-2.00 $\mathrm{M}$ showing first order corrosion reaction without changing the reaction mechanism. The results indicate that the extract of pandanus tectorius leaves acts as good and efficient inhibitor for corrosion of steel in $1 \mathrm{M}$ sulphuric acid and it was found that the maximum inhibition efficiency is $88.02 \%$ at $15 \%(v: v)$ and 1 hour of immersion. Potentiodynamic polarization studies revealed that the extract acts through mixed mode of inhibition. The impedance method revealed that charge-transfer process mainly controls the corrosion of steel. The adsorption of different concentrations of the plant extracts on the surface of steel in $1 \mathrm{M}$ sulphuric acid followed Langmuir adsorption isotherm. The negative sign of free energy of adsorption indicates that the adsorption of the inhibitor on steel surface was a spontaneous process and the adsorption was found to be physisorption. The SEM morphology of the adsorbed protective film on the steel surface has confirmed the high performance of inhibitive effect of pandanus tectorius leaves extract. The phenomenon of physical adsorption is proposed from a decrease in inhibition efficiency with an increase in temperature. The value of activation energy Ea revealed that the adsorbed organic matter provided a physical barrier to charge and mass transfer, leading to reduction in corrosion rate. The positive value of enthalpy of adsorption $\left(\Delta H^{*}\right)$ suggests that the reaction was endothermic and the adsorption of the inhibitors on the metal surface takes place. Large and negative values of $\Delta S^{*}$ in the uninhibited and inhibited systems imply that the activation complex in the rate determining steps represents association rather than dissociation step, meaning that a decrease in disordering takes place on going from reactants to the activated complex.

\section{Acknowledgements}

The author gratefully acknowledges to King Abdulaziz University, Girls College at KSA, Jeddah.

\section{References}

[1]. Jones, D. A. "Principles and Prevention of Corrosion", 2nd Edition, Prentice-Hall (1996).

[2]. Zhang, J.; Liu, J.; Yu, W.; Yan, Y.; You, L.; Liu, L. Corros. Sci. 2012, 52, 2059-2065.
[3]. Bothi, R. P.; Sethuraman, M. G. Mater. Corros. 2009, 59, 22-28.

[4]. Hmamou, D. B.; Salghi, R.; Zarrouk, A.; Hammouti, B.; Al-Deyab, S. S.; Zarrok, H.; Chakir, A.; Bammou, L. Int. J. Electrochem. Sc. 2012, 7 , 2361-2373.

[5]. Bothi, R. P.; Sethuraman, M. G. Mater. Lett. 2008, 62, 113-116.

[6]. Bothi, R. P.; Sethuraman, M. G. Pig. Res. Tech. 2009, 38, 33-37.

[7]. Senthil, K. A. N.; Tharini, M. G.; Sethuraman, K. Surf. Rev. Lett. 2009, 16 141-147.

[8]. Diraman, H.; Koru, E.; Digeklioglu, H. Israeli J. Aquaculture 2009, 61 134-142.

[9]. Hasanov, R.; Sadikoglu, M.; Bilgic, S. Appl. Surf. Sci. 2007, 253, 39133921.

[10]. Obot, I. B.; Obi-Egbedi, N. O. Colloid. Surface A 2008, 330, 207-212.

[11]. Znini, M.; Majidi, L.; Bouyanzer, A.; Paolini, J.; Desjobert, M. J.; Costa, J.; Hammouti, B. Arabian J. Chem. 2012, 5, 467-474

[12]. Khaled, K. F.; AI-Qahtani, M. M. Mater. Chem. Phys. 2009, 113, 150-158.

[13]. Ju, H.; Kai, Z. P.; Li, Y. Corros. Sci. 2008, 50, 865-871.

[14]. Sorkhabi, H. A.; Seifzadeh, D.; Hosseini, M. G. Corros. Sci. 2008, 50, 3363-3370.

[15]. Satapathy, A. K.; Gunasekaran, G.; Sahoo, S. C.; Kumar, A.; Rodrigues, P. V. Corros. Sci. 2009, 51, 2848-2856.

[16]. El Ouali, B.; Hammouti, B.; Aouiniti, A.; Ramli, Y.; Azougagh, M.; Essasi E. M.; Bouachrine, M. J. Mater. Environ. Sci. 2012, 3(1), 206-219.

[17]. Satapathy, A. K. Corrosion Sci. 2012, 65, 94-103.

[18]. Chaouki S.; Omar B.; Boufeldja T.; Lahcen L.; Yahia H. J. Mater. Environ Sci. 2012, 3(1), 206-219.

[19]. Ramananda, S. M.; Gurmeet, S. J. Mater. Environ. Sci. 2012, 3(4), 698705.

[20]. Whistler, A. Samoan Herbal Medicine. Honolulu, University of Hawaii. $1966,62$.

[21]. Walter, S. J. Q. Rev. Biol. 2000, 75(3), 322-331.

[22]. Whistler, W. A. Tongan Herbal Medicine, Honolulu: National Tropical Botanical Garden. 1992, 63.

[23]. Whistler, W. A. Polynesian Herbal Medicine, Hawaii: National Tropical Botanical Garden. 1992, 71.

[24]. Peungvicha, R. P. T.; Prasain, J. K.; Tezuka, Y.; Kadota, S. Thirawarapan, S. S.; Watanabe, H. J. Pharmacol. 1998, 62 (1), 79-84.

[25]. Shyamala, M.; Kasthuri, P. K. Int. J. Corros. 2012, 3(4), 1-13.

[26]. El-Hosary, A. A.; Saleh, R. M.; Shams-Eldin, A. M. Corros. Sci. 1972, 12 , 897-904.

[27]. Umoren, S. A.; Ekanem, U. F. Chem. Eng. Commun. 2010, 197(10), 1339-1356.

[28]. Abdel-Gaber, A. M.; Abd-El-Nabey, B. A.; Sidahmed, I. M.; El-Zayady, A. M.; Saadawy, M. Corros. Sci. 2006, 48(9), 2765-2779.

[29]. El-Etre, A. Y. J. Colloid Interf. Sci. 2007, 314(2), 578-583.

[30]. Vahirua-lechat, I.; Menut, C.; Roig, B.; Bessiere, J. M.; Lamaty, G. Phytochemistry 1996, 43(6), 1277-1279.

[31]. El-Awady, A.; Abd El-Nabey, B.; Aziz, A. S.; Khalifa, M.; Al-Ghanedy, H. Int. J. Chem. 1990, 1(4), 169-179.

[32]. Moretti, G.; Guidi, F.; Grion, G. Corros. Sci. 2004, 46(2), 387-403.

[33]. El-Etre, A.Y. Corros. Sci. 2003, 45(11), 2485-2495.

[34]. Li, Y.; Zhao, P.; Liang, Q.; Hou, B. Appl. Surf. Sci. 2005, 252(5), 1245 1253.

[35]. El-Etre, A. Y. Corros. Sci. 2003, 45(11), 2485-2495.

[36]. Aisha, M. T.; Al-Marhabi, N. M. Global J. Sci. Res. Chem. 2012, 12(1), 1 14.

[37]. Li, Y.; Zhao, P.; Liang, Q.; Hou, B. Appl. Surf. Sci. 2005, 252(5), 12451253.

[38]. Szauer, T.; Brandt, A. Electrochim. Acta 1981, 26, 1277-1260.

[39]. Zerga, B.; Attayibat, A.; Sfaira, M.; Taleb, M.; Hammouti, B.; EbnTouhami, M.; Radi, S.; Rais, Z. J. Appl. Electrochem. 2010, 10, 1-64.

[40]. Noor, E. A.; Al-Moubaraki, A. H. Mater. Chem. Phys. 2008, 110, 145154.

[41]. Guan, N. M.; Xueming, L.; Fei, L. Mater. Chem. Phys. 2004, 86, 59-68.

[42]. Orubite, K. O.; Oforka, N. C. Mater. Lett. 2004, 58(11), 1768-1772. 